\title{
FACTORS ASSOCIATED WITH MICROSPORIDIAL AND CRYPTOSPORIDIAL DIARRHEA IN HIV INFECTED PATIENTS
}

\author{
CORNET M.*, ROMAND S.*, WARSZAWSKI J.** \& BOURÉE P.*
}

\begin{abstract}
Summary :
Cryptosporidium and microsporidia are increasingly recognized as important agents of chronic diarrhea in human immunodeficiency virus $(H I V)$ infected patients. These protozoa present clinical and biological similarities but coinfection with these two parasites seems uncommon. In a population of diarrheic HIV infected patients in the Paris area (France), a comparison study was performed in order to clarify epidemiological differences between these protozoa. From November 1993 to December 1994, 26 microsporidial infected patients were compared to 28 cryptosporidial patients for various factors. Results of a multivariate logistic regression analysis showed that trips to tropical countries remained strongly associated with microsporidia compared with Cryptosporidium (adjusted odds ratio (OR) $=4.6,95 \%$ confidence interval (CI) 1.1-19.5). Thus, as compared with cryptosporidiosis, specific epidemiological factors could be associated with microsporidial transmission in tropical countries.
\end{abstract}

KEY WORDS : AIDS, Cryptosporidium, microsporidia, diarrhea, epidemiology

MOTS CLÉS : SIDA, Cryptosporidium, microsporidia, diarrhée, épidémiologie.

\section{INTRODUCTION}

$\longrightarrow$ hronic diarrhea is a common complication during the course of human immunodeficiency virus (HIV) infection. In this context, the two most frequently identified parasitic infections, microsporidiosis and cryptosporidiosis, present some clinical and biological similarities. Both of them are opportunistic protozoan parasites infecting the small bowel. Microsporidial and cryptosporidial diarrheal diseases occur in HIV infected patients when severe cellular immunodeficiency develops (CD4 cell counts $<100 / \mathrm{mm}^{3}$ ), during the later stages of acquired immunodeficiency syndrome (AIDS) (Current, 1991; Weber, 1994; Kotler, 1995). However, coinfection with these two parasites in the same patient seems to be

\footnotetext{
* Département de Parasitologie et Médecine Tropicale, Hôpital du Kremlin-Bicêtre, 78, rue du Général-Leclerc, 94275 Le KremlinBicêtre, France.

** Unité INSERM U292 Santé Publique et Épidémiologie, Hôpital du Kremlin-Bicêtre, 82, rue du Général-Leclerc, 94276 Le KremlinBicêtre Cedex, France.

Correspondance : Dr S. Romand. Tél. : (1) 45213321 - Fax (1) 45213319 .
}

Résumé : FACTEURS ASSOCIÉS AUX MICROSPIDIES ET CRYPTOSPORIDIES CHEZ DES PATIENTS DIARRHÉIQUES INFECTÉS PAR LE VIH

Les microsporidies et les cryptosporidies sont les principales causes parasitaires de diarrhée chronique chez les patients infectés par le virus de l'immunodéficience humaine (VIH). Malgré les similitudes cliniques et biologiques de ces protozoaires, l'association des deux parasites chez un même malade semble rare. Dans une population de sujets infectés par le VIH, les auteurs ont comparé les cas de microsporidiose aux cas de cryptosporidiose diagnostiqués de novembre 1993 à décembre 1994. Les résultats de l'analyse comparative de 26 patients porteurs de microsporidies et 28 porteurs de cryptosporidies montrent que les voyages en zone tropicale constituent un facteur significativement associé aux microsporidies, indépendamment des autres facteurs (Odds Ratio (OR) ajusté $=4,6$; Intervalle de Confiance (IC) à $95 \%: 1,7-19,51$. Les sujets originaires des pays tropicaux présentent également un risque augmenté de contamination par les microsporidies $(O R$ ajusté $=4,5 ;$ IC à $95 \%: 0,7-30)$. Ces résultats suggèrent, pour les microsporidies, l'existence de facteurs épidémiologiques distincts des cryptosporidies, pouvant favoriser leur transmission en milieu tropical. uncommon and some epidemiological differences could explain this fact (Houze-Savage, 1993; Wuhib, 1994). Human transmission, prevalence in tropical countries and risk factors for human infection with these protozoa are still uncertain, especially for microsporidia (Casemore, 1990; Current, 1991; Weber, 1994). A " case control " study was carried out among diarrheic HIV infected patients in order to compare microsporidial infected patients to cryptosporidial infected ones with regard to various different factors. The aim of this study was to highlight some possible epidemiological differences between these two infections in HIV infected patients.

\section{PATIENTS AND METHODS}

\section{PATIENTS AND PRESENTATION OF THE STUDY}

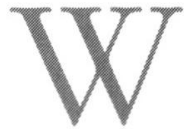
e conducted a 13 months study from November 1993 to December 1994 in the department of parasitology of the KremlinBicêtre hospital near Paris (France). The laboratory systematically performed all parasitic stool examinations, 
prescribed for abdominal pain or diarrhea, in HIV infected patients admitted to four hospitals in the Paris area. Patients were included in this study when Cryptosporidium or microsporidia were recovered from at least one stool sample. The group of microsporidial patients was compared to the cryptosporidial group for: country of origin, country of residence, trips to tropical areas, presence of animals, HIV exposure category, other opportunistic infections, CD4 T-cell counts before and at the moment of diagnosis, duration of diarrhea before diagnosis and coinfection with other intestinal pathogens.

\section{PARASITOLOGIC METHODS}

Both parasitic intestinal infections were diagnosed by stool examination.

For Cryptosporidium paruum, a concentrated stool specimen smear was stained using the acid-fast technique (Henriksen, 1981).

For microsporidia, two complementary methods were associated for each specimen because of the difficulty in detecting spores of these parasites. Stools were examined using Weber's chromotrope-based staining technique and the fluorescent technique described by Van Gool (Weber, 1992; Van Gool, 1993). A stool was considered positive if both stains revealed spores with typical morphology. Microsporidian species (Enterocytozoon bieneusi or Septata intestinalis) were not identified by electron microscopy.

\section{STATISTICAL METHODS}

Univariate analysis, Chi-square tests and Fisher's exact test were performed with the EPI INFO 5.0 software, produced by the Center of Disease Control (Atlanta, Georgia, USA). Logistic regressions analysis were performed using the Statistical Analysis System (SAS Institute, Cary, NC).

\section{RESULTS}

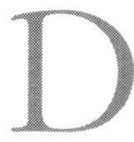

uring the 13 months-study period, 858 stool specimens were collected and analyzed from 383 diarrheic HIV infected patients. Cryptosporidium parvum oocysts were identified in 31 patients ( $8 \%, 95 \%$ Confidence Interval (CI) 5.310.7) and microsporidia spores in 29 patients $(7.6 \%$, $95 \%$ CI 4.9-10.2). Four patients (1\%, $95 \%$ CI 0.7-1.3) presented coinfection with the two parasites and were excluded from the comparison study. Three cases of cryptosporidiosis and three cases of microsporidiosis were also excluded because no data could be collected. Finally, 26 patients with microsporidial diarrhea were compared to 28 patients with cryptosporidial diarrhea.
The characteristics of the study population are summarized in table I. The ages ranged from four to 62 years (mean age: 36 years).

\begin{tabular}{lcc}
\hline & \multicolumn{2}{c}{ (\%) } \\
\cline { 2 - 3 } Feature & Men & Women \\
\hline & $n=46$ & $n=8$ \\
Age (years) & & \\
$\quad[0-17]$ & 4 & 0 \\
{$[18-24]$} & 2 & 0 \\
{$[25-44]$} & 76 & 75 \\
$>44$ & 18 & 25 \\
HIV exposure category & & \\
Homo/bisexual men & 67 & \\
Heterosexual & 15 & 62.5 \\
Drug IV & 9 & 25 \\
Hemophilic & 4 & \\
Feto-maternal & 2.5 & 0 \\
Homosexual + drug IV & 2.5 & \\
Accidental & & 12.5 \\
Country of origin & & \\
Tropical countries $\dagger$ & & \\
Western countries & 17 & 25 \\
Number of trips to tropical countries & & 75 \\
$\geq 1$ & 56 & 50 \\
0 & 44 & 50 \\
\hline
\end{tabular}

† Were considered as tropical countries: Sub-Saharan African countries, Central and South America, South-east Asia, West Indies and Pacific Islands.

Table I. - Characteristics of the study population in 54 HIV infected patients with microsporidial or cryptosporidial diarrhea: Paris, France, 1993-1994.

Univariate analysis did not show any significant difference between the two groups of infected patients for sex, age, CD4 T-cell counts, rank of the protozoan infection among other opportunistic infections or for contacts with animals (table II). Microsporidiosis was more associated with patients born in tropical countries than cryptosporidiosis (odds ratio $(\mathrm{OR})=5.8 ; 95 \%$ CI 0.9-45.6). Similarly, patients who traveled at least once or more to tropical countries were more likely to be infected with microsporidia (OR $=6 ; 95 \% \mathrm{CI}$ 1.6-24.3). The two groups were similar concerning the length of these trips, the date of return from the last trip before diagnosis and the conditions of stay abroad (comfortable or not). The occurrence of chronic diarrhea (over three months) was significantly higher for microsporidiosis than for cryptosporidiosis with means of seven and four months respectively.

A logistic regression analysis was performed, adjusting for all the significant factors found by univariate comparisons, also taking into account sex and rank of opportunistic infections which may reflect the stage of HIV infection (table III). Duration of diarrhea before 


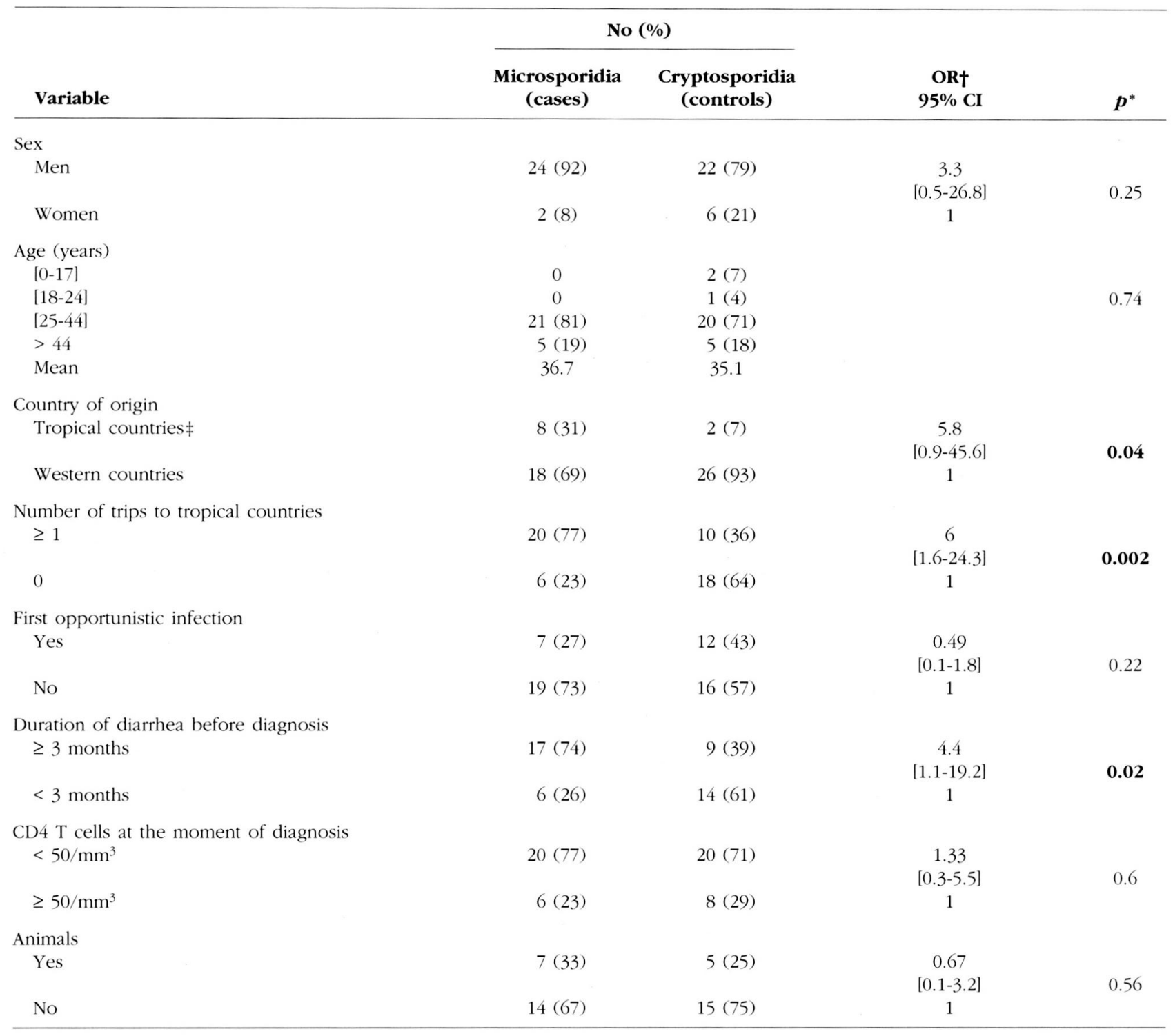

* Kruskall-Wallis' test or Fisher's exact test or chi-square test.

† Odds Ratio, $95 \%$ confidence interval.

‡ Were considered as tropical countries: Sub-Saharan African countries, Central and South America, South-east Asia, West Indies and Pacific Islands.

Table II. - Univariate analysis for factors associated with microsporidial and cryptosporidial diarrhea in 54 HIV infected patients: Paris, France, 1993-1994.

diagnosis, although being a significant factor in the univariate analysis, was unknown for eight patients and was not included into the final model. Multivariate analysis showed that trips to tropical countries remained independently associated with microsporidial diarrhea (adjusted $\mathrm{OR}=4.6 ; 95 \%$ CI 1.1-19.5). Patients born in tropical countries tended more likely to have microsporidiosis than cryptosporidiosis (adjusted $\mathrm{OR}=4.5$; $95 \% \mathrm{CI} 0.7-30$ ). Men also tended to have an increased risk for microsporidiosis (adjusted $\mathrm{OR}=7.7 ; 95 \% \mathrm{CI}$ 0.8-78).

\section{DISCUSSION}

Our results clearly show that, compared with HIVinfected patients with cryptosporidiosis, microsporidial infection was significantly more associated with previous travels to tropical areas among the same category of individuals. Moreover, this association remained significant even after controlling for confounding factors such as sex, country of origin, HIV exposure category and rank of opportunistic infection. Consistently, patients born in tropical countries also seemed to be 


\begin{tabular}{llc}
\hline \multicolumn{1}{c}{ Factor } & OR $(\mathbf{9 5} \% \mathbf{C I})^{*}$ & $\boldsymbol{p}$ value* \\
\hline & $n=54$ & \\
\hline Sex (men) & $7.7(0.8-78)$ & 0.08 \\
Trips to tropical countriest & $4.6(1.1-19.5)$ & $\mathbf{0 . 0 4}$ \\
Origin (tropical countriest) & $4.5(0.7-30)$ & 0.12 \\
HIV exposure category (sexual) & $2.2(0.3-15)$ & 0.40 \\
Rank of opportunistic infections & $4.2(0.97-18)$ & 0.05 \\
$(>1)$ & & \\
\hline
\end{tabular}

* Odds Ratio (95\% confidence interval).

† Were considered as tropical countries: Sub-Saharan African countries, Central and South America, South-east Asia, West Indies and Pacific Islands.

Table III. - Risk factors for microsporidial diarrhea comparatively to cryptosporidial diarrhea in a population of HIV diarrheic patients. Reduced models by multivariate logistic regression: Paris, France, 1993-1994

more at risk of microsporidiosis rather than cryptosporidiosis, although this association did not remain significant in the multivariate analysis. In that respect, compared with patients infected with Cryptosporidium, the higher proportion of microsporidia infected patients having stayed at least once in a tropical region must be of value since cryptosporidiosis itself is generally considered more frequent in developing tropical countries. Thus, most studies have reported strikingly high prevalences of cryptosporidiosis among immunocompetent and immunocompromised subjects living in tropical countries, and this was related with poor hygiene conditions resulting in increased fecal-oral contaminations (Malebranche, 1983; Henry, 1986; Crawford, 1988; Ungar, 1988). In addition, during the last few years, cryptosporidiosis has been repeatedly reported as a cause of traveler's diarrhea (Sterling, 1986). On the other hand, few data are currently available about the frequency of microsporidial related diarrhea in tropical countries. Yet, recent studies suggest that microsporidiosis could be a frequent disease in the developing world. Thus, in Zimbabwe, $11 \%$ of HIV-positive patients with diarrhea were found to be infected with E. bieneusi, which was the most prevalent parasite isolated (Van Gool, 1995), whereas prevalence of microsporidiosis was estimated at $23 \%$ among AIDS patients with chronic diarrhea in Zambia (Drobniewski, 1995). In another large study conducted in Niger, E. bieneusi spores were recovered from stools of 8/990 children who were not considered HIV positive, thereby suggesting a high prevalence of enteric carriage among immunocompetent persons in tropical countries (Bretagne, 1993). In addition, microsporidiosis has also been recognized as a cause of traveler's diarrhea in immunocompetent individuals returning from the Middle-East (Sandfort, 1994; Sobottka, 1995). Thus, our results are in agree- ment with the hypothesis of a high rate of transmission of microsporidiosis in tropical and sub-tropical areas.

By contrast, no significant difference was shown between cryptosporidial and microsporidial infected patients with regard to other different epidemiological factors, although our small sample sizes may not have allowed us to achieve statistical significance. Thus, opportunistic infections with these two protozoans may be considered as highly comparable, consistently with similar intestinal target and clinical spectrum of both infections (Current, 1991; Weber, 1994).

Some authors have suggested that Cryptosporidium may be sexually transmitted similarly to other protozoa such as Giardia intestinalis, Entamoeba bistolytica or Isospora belli (Phillips, 1981; Soave, 1984; Smith, 1988; Casemore, 1990; Sorvillo, 1994). In our study, the frequency of microsporidiosis was higher than cryptosporidiosis among sexually transmitted HIV patients, although the difference was not significant. In tropical countries, HIV contamination is mainly acquired through sexual contacts, hence tropical origin or trips may more probably explain the difference observed between microsporidial and cryptosporidial patients with regard to HIV sexual transmission.

The significant difference observed between the two pathogens for duration of diarrhea before diagnosis rather reflects the difficulty in detecting microsporidial spores. There was no significant difference in the CD4 lymphocyte counts between the two groups to explain the longer duration of microsporidial diarrhea.

Finally, although environmental sources of microsporidia are still unknown, this report raises the hypothesis of an increased risk of transmission of microsporidia in tropical countries as compared with Cryptosporidium, even though high prevalences of cryptosoridiosis are found in these countries. Since fecal-oral route of microsporidial transmission is most likely, poor hygiene conditions and possible increased environmental sources of infection in these countries could explain this finding. Therefore, in order to better define risk factors associated with microsporidiosis, carefully designed prospective epidemiological studies are needed, comparing patients infected and non infected with microsporidia.

\section{REFERENCES}

Bretagne S., Foulet F., Alkassoum W., Fleury Feith J. \& DeveLoux M. Prevalence of microsporidia spores in stools from children in Niamey, Niger. AIDS, 1993, 7 (suppl. 3): S34S35.

Casemore D. P. Epidemiological aspects of human cryptosporidiosis. Epidemiology and Infection, 1990, 104, 1-28. 
Crawford F. G. \& Vermund S. H. Human cryptosporidiosis Critical Reviews in Microbiology, 1988, 16, 113-159.

Current W. L \& Garcia L. S. Cryptosporidiosis. Clinical Microbiology Reviews, 1991, 4, 325-358.

Drobniewski F., Kelly P., Carew A., Ngwenya B., Luo N., PanKHURST C. \& FARTHING M. Human microsporidiosis in african AIDS patients with chronic diarrhea. Journal of Infectious Diseases, 1995, 17, 515-516.

Henriksen S. A. \& Pohlenz J. F. L. Staining of cryptosporidia by a modified Ziehl-Neelsen technique. Acta Veterinaria Scandinavia, 1981, 22, 594-596.

Henry M. C., De Clerq D., Lokombe B., Kayembe K., Kapiota B., Mamba K., Mbendi N. \& Mazebo P. Parasitological observations of chronic diarrhoea in suspected AIDS adults patients in Kinshasa (Zaïre). Transactions of the Royal Society of Tropical Medicine and Hygiene, 1986, 80, 309-310.

Houze-Savage S., Van Gool T., Bouchaud O., Geoffray C., Verdon R., Ruggeri C \& le Bras J. Parasites digestifs isolés dans les selles de patients VIH+ présentant une diarrhée chronique. Bulletin de la Société Française de Parasitologie, 1993, 2, 189-194.

KOTLER D.P. Gastrointestinal manifestations of HIV. Advances in Internal Medicine, 1995, 40, 197-242.

Malebranche R., Arnoux E., Guérin J.M., Pierre G.O., Laroche A.C., Péan-Guichard C., Elie R., Morisset P.H., Spira T., Mandeville R., Drotman P., Seemayer T. \& Dupuy J. Acquired immunodeficiency syndrome with severe gastrointestinal manifestations in Haiti. Lancet, 1983, ii, 873878.

Phillips S.C., Mildvan D., William D.C., Gelb A.M \& White M.C. Sexual transmission of enteric protozoa and helminths in a veneral-disease-clinic population. New England Journal of Medicine, 1981, 305, 603-606.

Sandfort J., Hannemann A., Gelderblom H., Stark K., Owen L.R. \& Ruf B. Enterocytozoon bieneusi infection in an immunocompetent patient who had acute diarrhea and who was not infected with human immunodeficiency virus. Clinical Infectious Diseases, 1994, 19, 514-6.

Smith P.D., Lane H.C., Gill V.G., Manischewitz J.F., Quinnan G.V \& Fauci A.S. Intestinal infections in patients with the acquired immunodeficiency syndrome (AIDS). Etiology and response to therapy. Annals of Internal Medicine, 1988, 108, 328-333.

Soave R., Danner R.L., Honig C.L., Ma P., Hart C.C. \& NASH T. Cryptosporidiosis in homosexual men. Annals of Internal Medicine, 1984, 100, 504-511.

Sobottka I., Albrecht H., Schottelius J., Schmetz C., BentFeld M., Laufs R. \& SChawarTz D.A. Self-limited traveller's diarrhea due to a dual infection with Enterocytozoon bieneusi and Cryptosporidium parvum in an immunocompetent HIV-negative child. European Journal of Clinical Microbiology and Infectious Diseases, 1995, 14, 919-920.

Sorvillo F.J., Lieb L.E., Kerndt P.R. \& Ash L.R. Epidemiology of cryptosporidiosis among persons with acquired immunodeficiency syndrome in Los Angeles county. American Journal of Tropical Medicine and Hygiene, 1994, 54, 326331.
Sterling C.R., SeEgar K. \& Sinclair N.A. Cryptosporidium as a causative agent of traveler's diarrhea. Journal of Infectious Diseases, 1986, 153, 380-381.

Ungar B.L.P., Gilman R.H., Lanata C.F. \& Perez-Schael I. Seroepidemiology of Cryptosporidium infection in two latin american populations. Journal of Infectious Diseases, $1988,157,551-556$.

Van Gool T., Snidjers F., Reiss P., Eeftinck Schattenkerk J.K.M. \& Van Den Bergh Weerman M.A. Diagnosis of microsporidial infections in patients with HIV by a new rapid fluorescent technique. Journal of Clinical Pathology, 1993, 46, 694-699.

Van Gool T., Luderhoff E., Nathoo K.J., Kirre C.F., Dankert J. \& MANSON P.R. High prevalence of Enterocytozoon bieneusi infections among HIV-positive individuals with persistent diarrhoea in Harare, Zimbabwe. Transactions of the Royal Society of Tropical Medicine and Hygiene, 1995, 89, 478480 .

Weber R., Bryan R.T., Owen R., Wilcox M., Gorelkin L. \& Govinda S. Improved light microscopal detection of microsporidia spores in stool and duodenal aspirates. New England Journal of Medicine, 1992, 326, 161-166.

Weber R., Bryan R.T., Schwartz D.A. \& Owen R.L. Human microsporidial infections. Clinical Microbiology Reviews, 1994, 7, 426-461.

Wuhib T., Silva T.M.J., Newman R.D., Garcia L.S., Pereira M.L.D. \& Chaves C.S. Cryptosporidial and microsporidial infections in human immunodeficiency virus infected patients in Northeastern Brazil. Journal of Infectious Diseases, 1994, 170, 494-497.

Reçu le 29 novembre 1995 Accepté le 26 septembre 1996 